\title{
Creating controversy
}

As scientists, we sometimes find it hard to imagine that fundamental biological concepts such as evolution are still questioned by significant sectors of society. But evolution clearly is. A recent CBS news poll found that $55 \%$ of US residents held the view that "God created humans in present form"; $27 \%$ chose "humans evolved, God guided the process"; and 13\% believed that "humans evolved, God did not guide process" (see http://www.cbsnews.com). Even more surprising is that the percentage of people holding these views has not significantly changed over the past 20 years, according to a similar poll by Gallup (showing 45\%). This is a substantial proportion of the population and certainly extends beyond strict scriptural literalists.

Why is the general public - at least within the US - so skeptical of evolution? The answer is obviously complex. One significant aspect is that most of the public have never been taught evolution comprehensively, mostly relying on cursory explanations in high school or random coverage in the popular press. Thus, there are a lot of widely held misconceptions about evolution. One of the most damaging is that religious beliefs are incompatible with the basic tenets of evolution, preventing individuals from approaching the concepts of evolution with an open mind. Indeed, the understanding of evolution does not necessitate an atheistic perspective, and most mainstream Christian denominations - including a public statement from Pope John Paul II - do not view evolution as being in conflict with their notions of faith. So, many Americans that reject evolution on the basis of their religious beliefs do so in contrast to the teachings of their church.

One reason for the persistence of these misconceptions is that the anti-evolution movement has propagated them as a means to discredit evolution. In the US, because most attempts to incorporate 'creation science' into the curriculum of public schools have been defeated in the courts on constitutional grounds of separation of church and state, the anti-evolution movement has switched to more subtle tactics that avoid overt statements about religion. Instead of promoting creationism as science, the new creationist tactics focus more on trying to discredit evolution. By misrepresenting evolutionary theory (and indeed Darwin's own writings), or by citing, out of context, specific points from legitimate scientific debates over the mechanisms of evolution, the anti-evolutionists are attempting to portray evolution as 'just' a theory, and a controversial one, to non-scientific audiences.

In addition to discrediting evolution, opponents to evolution in the US are increasingly proposing 'Intelligent design' as an alternative theory. This proposes that biology is so complex that it cannot be explained by genetic mutation and natural selection, even acting over millions of years, and must therefore be the product of intelligent design - implying God without strictly stating so (see Wired, October 2004). Thus, the current spectrum of anti-evolutionist groups runs from those promoting strict scriptural literalism to those simply attacking the theory of evolution, although most seem to still be motivated by fundamentalist Christian beliefs (see http:// www.natcenscied.org/). Another current strategy is to argue that as evolution is 'controversial', both sides of the controversy should be taught, appealing to the ideals of fairness. 'Intelligent design' seems to be the favoured 'alternative theory' currently being pushed in the US.

Of course, there is no scientific controversy over the basic tenets of evolution, and 'Intelligent design' has not been shown valid by any scientific criterion. Even so, the anti-evolution movement has had recent success with local school boards in the US. For example, the Cobb County School District in Georgia mandated that a disclaimer, stating that "evolution is a theory, not a fact, regarding the origin of living things" be inserted into appropriate textbooks. This policy is currently under challenge in the US District Court. Also under court challenge is an October 2004 decision by the Dover Area School Board in Pennsylvania requiring biology teachers to present 'Intelligent design' as an alternative to evolution.

By contrast, the anti-evolution movement in Europe seems to be less expansive and less effective. This is perhaps due to lower numbers of Christian fundamentalists but may also be because there is less local control of European school curricula. Despite this, there are increasing examples of anti-evolutionist activity. In the UK in 2003, privately sponsored academies (which also receive significant public funds) of the Vardy Foundation made the news for teaching creationism along with evolution. In September 2004, the Serbian education minister, Lijiljana Colic, ordered that evolution no longer be taught to 14-15year-old students, and said that evolution would not be taught in future years unless given equal time with creationism. This policy was, however, overturned within days by the government. Similarly, in Italy, the proposal to remove evolution from the curriculum for 11-14year olds - while retaining the teaching of creationism in voluntary religious classes - was reversed on the advice of a specially convened committee, prompted by criticism from the scientific community.

The anti-evolution movement, particularly within the US, is well mobilized and skilled at circumventing scientific scrutiny by going directly to legislators and the public. It is also very much a grass roots movement that preferentially targets local institutions. So, we as scientists should pay close attention to what is going on locally and get involved. The subtle tactics used by 'Intelligent design' adherents relies on the scientific naivety of their audience to present 'Intelligent design' as a legitimate alternative to evolution. By speaking up, scientists can ensure that the debate is based on fact.

The ultimate goal is to improve the public's understanding of evolution. Although more complex than popularly perceived, the basic tenets of evolution can easily be explained to the average citizen (see National Geographic,November2004). Withwidespreadunderstandingofthebasic facts, widespread acceptance of the basic tenets of evolution is assured. 